\title{
MALES Y REMEDIOS DE LA CIUDAD MODERNA: PERSPECTIVAS AMBIENTALES DE LA EUGENESIA ARGENTINA DE ENTREGUERRAS
}

\author{
Gustavo Vallejo \\ CONICET. IIB-INTECH. \\ Universidad Nacional de General San Martín (Argentina)
}

\section{RESUMEN}

Durante el período de entreguerras se consolidó en Argentina una tendencia a patologizar la ciudad moderna, entendida como un organismo enfermo que producía y a su vez era consecuencia de la decadencia física y moral de sus habitantes. La interrupción de la inmigración externa aportó nuevos datos para una estrategia de regeneración que pugnó por establecer, desde la eugenesia, medidas dirigidas a articular el poblacionismo con la distribución territorial, en la certeza de que el campo contrarrestaría los males que generaba la vida moderna. El trabajo repasa el impacto de esta ideología en distintas esferas y el modo en que ella se recepcionó junto a la política cultural del fascismo y formó parte del corpus con el que la biotipología buscó darle legitimidad científica.

PALABRAS CLAVE: Ciudad moderna, biopolítica, eugenesia, biotipología, ambiente, población, fascismo.

\section{DISEASES AND REMEDIES IN MODERN CITY: ENVIRONMENTAL PER- SPECTIVES OF ARGENTINIAN EUGENISM BETWEEN THE MUNDIAL WARS}

\begin{abstract}
During the inter - war period it consolidate in Argentina a tendency to pathologize the modern city, understood like an ill organism that produced and was consequence phisical and moral decadency of its habitants. The interruption of external inmigration contributed with new information for a strategy of regeneration that tried to establish from eugenesics directed to articulate the populationism with the territorial distribution, in the certainty that counteracted country the evils that generated the life modern. The work reviews the impact of this ideology in the different spheres and the way in which has integrated the cultural politic of the fascism and taked part of the corpus with which the biotipology looked to give scientific legitimacy.
\end{abstract}

KEY WORDS: Modern city, biopolitics, eugenics, biotipology, enviroment, population, fascism. 


\section{DE LA HIGIENE A LA EUGENESIA: LA BIOPOLÍTICA}

En el marco de la aguda crisis en la que entró la Argentina tras sufrir el impacto periférico del crac económico internacional de 1929, sobrevino una situación signada por inéditas consecuencias sociales y políticas: por un lado la drástica interrupción del flujo inmigratorio determinó que por primera vez en el siglo $\mathrm{XX}$ se alterara un sostenido crecimiento demográfico y por otro lado, la depresión económica pronto derivó en el primer quiebre institucional y en un claro alineamiento ideológico con la realidad política italiana.

Estos dos hechos se amalgamaron para afianzar la integración al Estado de la biopolítica, en tanto tecnología de poder que ubica la raza como fundamento de estrategias de articulación de la vida biológica con la producción ${ }^{1}$ y que, en su versión «latina», presentó explícitas metáforas que aunaron la biología con el corporativismo social. Estas cuestiones venían siendo debatidas por la cultura científica argentina con especial énfasis desde la primera posguerra europea, cuando la eugenesia fue propagándose para revertir el decaimiento atribuido a la civilización occidenta ${ }^{2}$. Pero ahora la nueva coyuntura nacional

1 Foucault, M. (2001), Defender la sociedad, (Curso en el Collège de France, 19751976, primera edición en francés, 1997), Buenos Aires, Fondo de Cultura Económica. Véase especialmente «Clase del 17 de marzo de 1976», pp.217-237; y FouCAulT, M. (2004), Naissance de la biopolitique (Cours au Collège de France, 1978-1979), Paris, Gallimard Seuil.

2 En el análisis histórico de la eugenesia han sido precursores los trabajos de Álvarez Peláez, centrados principalmente en la figura de su creador, Francis Galton y en el impacto de esa disciplina en España y Cuba: Álvarez Peláez, R. (1985), Sir Francis Galton, padre de la eugenesia, Madrid, CSIC; Álvarez PelÁEz (1988), Francis Galton. Herencia y Eugenesia, Madrid, Alianza Universidad; Álvarez PelÁEz (coord.) (1999), Dossier "Estudios sobre Eugenesia", Asclepio 51 (2), 5-148; y García GonzÁlez, A. y Álvarez Peláez, R. (1999), En busca de la raza perfecta, Madrid, CSIC. Para un abordaje de la eugenesia en un plano comparado entre México, Brasil y Argentina durante las décadas de 1930 y 1940, véase STEPAN, N. (1991), The hour of eugenics. Race, gender and nation in Latin America, Ithaca and London, Cornell University Press. Son mas recientes los estudios sobre la eugenesia en Argentina, entre los que pueden citarse: SCARZANELLA, E. (1999), Italiani malagente. Inmigrazione, criminalità, razzismo in Argentina, 1890-1940, Milano, Franco Angeli; MIRANDA, M. (2003); «La antorcha de Cupido: eugenesia, biotipología y eugamia en Argentina, 1930-1970», Asclepio 55 (2), 231255; VALlEJO, G. y MiRANDA, M. (2004), «Los saberes del poder: Eugenesia y Biotipología en la Argentina del siglo XX», Revista de Indias 64 (231), 425-444; VALLEJO, G. (2004), «El ojo del poder en el espacio del saber: los Institutos de Biotipología», Asclepio 56 (1), pp.219-244; Palma, H. (2005), Gobernar es seleccionar. Historia y reflexiones sobre el mejoramiento genético en seres humanos, Buenos Aires, Baudino. Asimismo trabajos que abordan el caso argentino pueden hallarse en Miranda, M. y VAlLejo, G. (comp.) (2005), Darwinismo social y eugenesia en el mundo latino, Buenos Aires, Siglo XXI. 
e internacional gestada hacia 1930, establecía un estado de cosas por demás propicio para ubicar la biopolítica al servicio de acciones dirigidas a legitimar interpretaciones corporativas conducentes a contrarrestar consecuencias indeseadas de la crisis ${ }^{3}$. Entre éstas últimas, ocupaban un lugar especial aquellos datos de la realidad que integraban los problemas de la masificación urbana, las enfermedades sociales que debilitaban al cuerpo social, el descenso demográfico y la posibilidad de compensar la interrupción del «aluvión inmigratorio» con políticas pro-natalistas, desplegadas sobre un universo homogéneo de individuos que forjen la verdadera «raza argentina» ${ }^{4}$.

La situación no escapaba a la influyente perspectiva de Leopoldo Lugones, en gran medida uno de los artífices intelectuales del nuevo orden político instituido por el General Uriburu, al que le señaló, tras el Golpe, la necesidad de aprovechar el impasse y diseñar estrategias para que la reanudación de la inmigración permita seleccionar los «elementos que hayamos de incorporar, en atención a su eficacia productiva y fecunda, y la determinación correlativa de su raza» ${ }^{5}$. Asimismo destacaba que «la bastardía nacional existe y que la heterogeneidad de elementos inmigrados resulta desventajosa. Podemos y debemos, pues, adoptar preferencias, no sólo en lo concerniente a la capacidad económica, salud y estado civil del inmigrante, sino a su carácter étnico». ${ }^{6} \mathrm{Y}$ en ese sentido, el criterio de la selección debía partir de una drástica sentencia: «somos la raza latina y nos conviene serlo» debido a que «formamos parte integrante del Imperio Romano» ${ }^{7}$.

3 La relación entre biopolítica y eugenesia, con sus proyecciones sobre la realidad española de la primera mitad del siglo XX puede verse en ÁlvAREZ PELÁEZ, R. (2005); «Eugenesia, ideología y discurso del poder en España», en MirandA, M. y VALLEJO, G. (comp.), pp. 87-114. Asimismo, la biopolítica vista a través de su relación con el racismo y la vida moderna, partiendo de las formulaciones de Foucault, tiene distintas derivaciones en autores italianos: ESPOSITO, R. (2002), Bios, politica e filosofia, Torino, Einaudi; PADOVAN, D. (2003); «Bio-politica, razzismo e disciplinamento sociale durante il fascismo», http://www.sissco.it/attivita/sem-set2003/relazioni/padovan.rtf; CUTRO, A. (2004), Michel Foucault. Tecnica e vita. Bio-politica e filosofia del bios, Napoli, Bibliopolis. Por su parte, sobre la relación entre biopolítica y ciudad en países latinoamericanos puede verse: OUTTES, J. (2003); «Disciplining Society through the City. The Genesis of City Planning in Brazil and Argentina (1894-1945)», Bulletin of Latin Amewrican Research 22 (2), pp. 137-164.

4 Miranda, M. (2005), «La biotipología en el pronatalismo argentino (1930-1983)», Asclepio 57 (1), pp. 189-218.

5 Lugones, L. (1949), «La grande Argentina» (1930), Antología de la prosa (Selección y comentarios de Leopoldo Lugones, hijo), Buenos Aires, Centurión, pp. 429-451, p. 441.

6 Ibidem, p. 442.

7 Ibidem, p.443. 
Desde esta perspectiva, la crisis ofrecía una oportunidad para salir de ella en forma superadora, esto es, evitando los peligros latentes para el orden social que eran vistos en las democracias representativas. La experiencia corporativa italiana pasó a ser un horizonte de ideas cada vez más ligado a la cultura política argentina, no sólo por el ímpetu de un Lugones anhelante de una reconstrucción imperial que reúna la raza latina, sino porque similares coordenadas atravesaron la convicción de hombres de Estado que encontraron legitimidad dentro del campo científico. Especialmente a través de importantes espacios para gestar mecanismos de control social basados en estrategias biopolíticas que llevaban el sello de la eugenesia italiana.

En efecto, la coyuntura contribuyó a que entre las esferas del poder y del saber se acentuaran interacciones que permitieron tejer una sólida amalgama, fundada en la convicción de que actuar en pos de una raza fuerte era un imperativo para la Argentina que debía asumir enfáticamente su pertenencia dentro de la órbita del mundo latino. Fue ese un remanido recurso argumental que instó a desplegar durante la «década infame» (1930-1943) y con la legitimidad que confería la invocación de la ciencia, acciones que expandieron el abordaje de la sanidad humana hacia diferentes ámbitos de actuación. Ellos quedaron integrados por los vastos alcances que adquiría la noción de eugenesia y particularmente su recepción local asociada a la idea de «Biología política» o «Política sobre bases biológicas», como primera definición de la biotipología.

Ya desde comienzos del siglo XX, frente a la ciudad y los problemas desbordantes que la modernidad traía aparejados, el higienismo había indicado en Argentina, como en otros países, el camino de un proceso de medicalización que excedía el plano individual para proyectarse hacia prescripciones de índole colectiva a través de la salud pública. La amplia receptividad que tuvo la «Escuela positiva» lombrosiana complementaba este proceso allanando la apertura de nuevos campos de actuación para que esa medicalización interviniera decisivamente en la detección del crimen y la locura, al proporcionar - como se creía - la posibilidad de descifrar los contenidos internos del hombre a través de su apariencia externa. A su vez, la inquietud por detener la propagación de aquello que Víctor Delfino calificó como «venenos sociales», aludiendo al alcohol, la sífilis y la tuberculosis, y el afán por «corregir» el ambiente que favorecía su reproducción, hizo focalizar la atención en el mundo urbano, escenario de una «mala vida», ${ }^{8}$ asociada en Buenos Aires al con-

8 Sobre el tema pueden seguirse las versiones italiana, española y argentina: NICEFORO, A. y Sighele, E. (1898), La mala vita a Roma, Torino; BERnARdo DE Quirós, C. y LlanAS, 
ventillo y a la calle, donde abundaba la «simulación» creada para valerse de la asistencia pública y sobrevivir en la «lucha por la vida»9.

La vasta constelación de temas que cada una de estas cuestiones suscitó, quedó integrada a una agenda social que desbordó al higienismo y requirió trascender las formas tradicionales de asistencia que él prolongó. El punto culminante de los afanes higienistas puede hallarse en textos de la última etapa de Emilio Coni, que reflejan un esfuerzo por tutelar el estado de salud de toda la comunidad y se sintetizan en 1919 en su utopía de «la ciudad del porvenir», que era en última instancia la utopía del capitalismo mejorado. En sus prefiguraciones, ella tendría precisas características formales, similares a la nueva ciudad de La Plata, en la que Coni participó de su plan fundacional ${ }^{10}$, pero sólo como parte de un programa mayor dirigido a sistematizar una amplia malla de ámbitos sanitarios y educacionales controlados por el Estado. A la disponibilidad de abundante agua potable, se sumaba la permanente inspección de médicos y arquitectos sanitaristas para garantizar que todas las casas cumplimentaran normas de estética, higiene y confort, dentro de una ciudad donde ya no habría conventillos sino barrios obreros con viviendas

J. (1901), La mala vida en Madrid. Estudio psico-sociológico, Madrid, B. Rodríguez Serra; y Gómez, E. (1908), La mala vida en Buenos Aires, Buenos Aires, Juan Roldán. Recientes trabajos analizaron agudamente los discursos científicos sobre la «mala vida» en la delincuencia infantil de comienzos de siglo XX en España y Brasil: HuERTAS, R. (2005), «La medicalización de la delincuencia infantil en la España del primer tercio del siglo XX» en MiRANDA, M. y VALleJo, G. (comp.), pp. 375-400, y FerLA, L. (2005), «El niño, el médico, el policía y el patrón. Infancia y determinismo biológico en el Brasil de entre-guerras», en MIRANDA, M. y VALLEJO, G. (comp.), pp. 401-440.

9 En Argentina José Ingenieros puso en discurso a la «simulación» vista desde una perspectiva sociodarwinista con su tesis doctoral publicada en 1903. El «simulador» se confundía en el magma de la vida moderna y evitaba con engaños que sea reconocido el lugar que le correspondía ocupar en la sociedad, a modo de estrategia de supervivencia en la lucha por la vida. La obra tuvo una casi simultánea edición en Torino que ratificó los intensos vínculos de Ingenieros con la «Escuela positiva» y los primeros esbozos de organización de la eugenesia en Italia. En la edición de 1904, Ingenieros agregó la nota a pie donde indica que ideas suyas «acaban de ser confirmadas por el movimiento eugénico rápidamente difundido». INGENIEROS, J. (2003), La simulación en la lucha por la vida (primera edición, 1903), Buenos Aires, Losada, p.132. Para un profundo estudio sobre el sentido que Ingenieros le dio al concepto de «simulación» véase Huertas GarcíA-Alejo, R. (1991), El delincuente y su patología. Medicina, crimen y sociedad en el positivismo argentino, Madrid, CSIC. Después de tener varias reediciones internacionales, el texto de Ingenieros fue reinterpretado en España (aunque sin citarlo) por VALLEJo NÁGERA, A. (1934), La simulación de la enfermedad, Madrid, Cenit.

10 Vallejo, G. (2006), Escenarios de la cultura cientifica argentina: ciudad y universidad (1882-1955), Tesis doctoral. 
«higiénicas y sonrientes». Y debido a ello «la raza será mejorada, física y moralmente» ${ }^{11}$. Lavaderos comunitarios y Casas de baño concebidas como nuevas termas romanas, se sumarían a la batería de servicios higiénicos dentro de un programa estatal que, además, anhelaba crear numerosos espacios verdes para aumentar «la capacidad respiratoria de los centros de población». Asimismo, una "oficina central de informaciones para las obras de beneficencia y previsión social» sería una suerte de panóptico, pero no de los casos excepcionales - o enfermos - sino de la población urbana en general desde donde se controlaba la salud y se prevenía la enfermedad de la comunidad urbana ${ }^{12}$.

Pero paralelamente a esta utopía, Coni también llegó a descubrir los propios límites que podía tener la acción asistencial inclusiva dentro de una sociedad industrial compleja. El Buenos Aires «caritativo y previsor» que describió en forma simultánea, era escenario de una interminable red asistencial descripta minuciosamente en 700 páginas que abruptamente culminan con la delimitación del universo de la inclusión, a través de un llamativo apéndice que contiene una encuesta sobre «Retardados escolares» remitida a Directores de escuelas primarias ${ }^{13}$.

La «ciudad del porvenir» excluía las más profundas anomalías, aquellas que ponían en riesgo su armonía y debían tratarse particularizadamente fuera del contexto urbano. Como los «retardados», un «armamento antituberculoso» instaba a segregar los «niños débiles» a «sanatorios de llanura, de montaña y de mar» y a «colonias agrícolas» que prepararían la reinserción urbana de los mejorados. Asimismo, colonias de vacaciones complementarían el tratamiento sanitario ${ }^{14}$.

En la búsqueda de la optimización de recursos regulando exclusiones, definiendo universos homogéneos de asistencia y colocando la raza como fin

11 Coni, E. (1919), «La ciudad argentina ideal o del porvenir», La Semana Médica 1, Buenos Aires, pp.342-345.

12 ARMus, D. (1999), «La ciudad higiénica: tuberculosis y utopías en Buenos Aires», en Gutman, M. y Reese, T. (ed.), Buenos Aires 1910. El imaginario para una gran capital, Buenos Aires, EudEBA, pp.97-110.

13 Coni, E. (1918), Higiene social. Asistencia y previsión social. Buenos Aires caritativo y previsor, Buenos Aires, E. Spinelli, Véase especialmente pp.702-703. Coni allí revelaba el intento por detectar anomalías en ese Buenos Aires «caritativio y previsor» de las que debía prescindir, enviándolas eventualmente a la red de Asilos que fuera del mundo urbano ya había montado Domingo Cabred, por entonces Presidente de la Comisión de Asilos y Hospitales Regionales. Véase CABRED, D. (1918), Discursos sobre Asilos y Hospitales regionales en la República Argentina, Buenos Aires, Talleres gráficos Weiss y Preusche.

14 Coni cfr. ARmus (1999), p.108. 
último de estas acciones, aparecía la biopolítica, con la promesa de llegar más allá de donde lo hacía la higiene interviniendo sobre la cultura urbana. Se trataba ahora de diseñar mecanismos más sutiles, económicamente más racionales que la asistencia a granel, a la vez masiva y con lagunas, que, más que avanzar hacia la universalidad de derechos, tendía a prolongar la noción de caridad cristiana ${ }^{15}$.

Y esta redefinición cabe verla en Argentina en el mismo momento en el que Coni enunciaba su utopía de «la ciudad del porvenir»: ella surgió, en efecto, como respuesta a una solicitud formulada por el director de la revista La Semana Médica, Víctor Delfino, por ser aquel «ilustre higienista» quien se encontraba en mejores condiciones para «trazar el plan a que debe sujetarse la ciudad argentina ideal o del porvenir en sus múltiples fases de situación, construcción, estética, viabilidad, higienización, saneamiento, asistencia y previsión social». En su creciente preocupación por la prevención, la higiene urbana propendía avanzar desde las características físicas de la ciudad para dirigirse hacia el control sanitario generalizado y constante. $Y$ este proceso que fue de lo individual a lo colectivo, de la atención a las demandas específicas del paciente a la imposición de normas higiénicas para toda la comunidad, donde Coni podía autodefinirse como un «médico de ciudades antes que de personas» ${ }^{16} \mathrm{y}$ que en definitiva fue de la cura a la prevención, encontró una directa articulación con la posterior inquietud por ejercer un rol predictivo sobre las sociedades humanas. Vale decir que allí donde terminaban los alcances de la higiene se sitúa el punto de partida para el inicio de un nuevo campo de exploraciones, en el que cabe encuadrar las motivaciones de una solicitud de Delfino que tuvo la respuesta esperada. Aquella que podía claramente empalmar los deseos aún incumplidos de Coni y las expectativas depositadas para articular el fin último de la higiene con el nacimiento de una nueva utopía: la eugenesia.

El paso de la medicina curativa a la preventiva, traía aparejado el impulso hacia instancias predictivas que permitirían anticiparse a la necesidad de curar y prevenir interviniendo con exclusiones dirigidas sobre la etapa prenatal y/o infantil. La eugenesia conllevaba la aplicación de un ideal de pureza y homogeneidad, convertido en un verdadero antídoto científico a las principales causas de desborde social expresadas en las ciudades modernas, desde su propia esencia constitutiva que era la de anticiparse al crimen, al delito y a

15 Foucault (2001), p. 221.

16 Coni, E. (1918), Memorias de un médico higienista, Buenos Aires, Talleres gráficos Flaiban, p. 68. 
toda forma de degeneración, a través de selecciones realizadas a tiempo para identificar y excluir aquello que ponía en riesgo la esfera de normalidad.

Ese era el trayecto que Delfino buscaba afianzar para articular una y otra utopía: la asistencial del higienismo con la predictiva de la eugenesia, que prometía resolver la imposibilidad de ampliar indefinidamente la inclusión social evitando gastos inconvenientes al Estado. El contenedor físico idealizado a futuro, «la ciudad del porvenir» venía así adunado a una referencia a su contenido poblacional, «la verdadera raza argentina», a través de una directa articulación entre formas y comportamientos deseados, entre ciudad moderna y población, que será un rasgo distintivo de la eugenesia argentina, especialmente a partir de 1930.

Delfino desde 1918 impulsaba la creación de la Sociedad Eugénica Argentina, tras haber sido el representante oficial de ese país en el Primer Congreso Internacional de Eugenesia, celebrado en 1912 en Londres bajo la dirección de Leonard Darwin (hijo de Charles) y atesorar dentro de ese campo una importante inserción en instituciones científicas del más alto nivel internacional. La guerra europea había interrumpido la realización del Segundo Congreso Internacional y en el plano específico de las redes ya constituidas en torno a la eugenesia, ello derivó en una cierta dispersión referencial que diluía un tanto el protagonismo local de Delfino, al tiempo que favorecía el posicionamiento dentro de este campo de otras figuras vinculadas a las élites intelectuales y políticas de Buenos Aires ${ }^{17}$.

En este sentido, la apuesta de Delfino por su Sociedad Eugénica buscaba reposicionarlo ante el hecho constatable de que el Museo Social Argentino, más que una institución influyente en el poder, el poder mismo organizado en una institución; ya había hecho suyo este cuerpo de ideas que trascendían así el campo específicamente médico ${ }^{18}$.

En su cruzada contra los «venenos sociales», Delfino fue articulando una respuesta holística a los males urbanos que, como en el caso de Coni, con-

17 En julio de 1914 Víctor Delfino fue convocado para organizar la delegación argentina al Segundo Congreso Internacional de Eugenesia, previsto para setiembre de 1915 en el Museo Americano de Historia Natural de New York con la Presidencia de Alejandro Graham Bell y Henry Fairfield Osborn. El Comité consultivo argentino quedó conformado por Genaro Sisto (Presidente), Alfredo Palacios (Vicepresidente), Víctor Arreguine (Secretario General), Víctor Delfino (Tesorero), y Ricardo Calatroni, Marcelino Herrera Vegas, Pedro L. Baliña y Mariano R. Castex (Vocales). Igualmente el encuentro recién pudo llevarse a cabo en 1921, donde Delfino fue el único representante de Sudamérica.

18 Además de distintas Secciones del Museo Social en las que la eugenesia ocupó un lugar central, cabe destacar que sus objetivos pernearon la realización en 1919 de la «Encuesta sobre la inmigración deseable», entre importantes figuras del campo intelectual y político. 
cluía en la necesidad de detectar y excluir anormalidades para liberar de «injustificadas» cargas al Estado y definir sobre ellas especiales estrategias. En 1920 Delfino asumió la dirección del Instituto Tutelar de Menores para afianzar una carrera científica dedicada al estudio de «la curiosa psicología de los niños desviados hacia el vicio o la holgazanería, procurando con acierto enderezar esos árboles jóvenes torcidos». ${ }^{19}$ Así describía Aráoz Alfaro su accionar que veía a su vez como el complemento necesario para desplegar una preocupación por «la infancia moral y físicamente sana para formar la raza fuerte y bella del mañana» en paralelo con la constitución de la Sociedad Eugénica Argentina ${ }^{20}$.

Delfino encontraba el origen de la criminalidad infantil en «la influencia nefasta de nuestro gran puerto, que vuelca en la metrópoli elementos de dudosa moralidad y el tráfago de la ciudad tentacular con la proterva caravana de sus vicios», que impiden "al obrero de uno y otro sexo, vigilar a su progenie» ${ }^{21}$. Frente a estos males el Instituto Tutelar de Menores concebido como una Villa-Hogar y a la vez una Colonia Open-Door en medio del campo, aparecía como un «foco de redención moral» para que «los depravados se purifiquen» y «se mejoren los precoces», devolviendo «a la sociedad las células desagregadas de la familia ciudadana, libres de sus tachas y de sus deplorables tendencias ${ }^{22}$. Sería un importante «factor de profilaxis y saneamiento social en la lucha contra las determinaciones morbosas hereditarias de la infancia y del ambiente social», un índice de progreso «necesario para nuestra gran metrópoli y para el futuro de nuestra raza» ${ }^{23}$.

Las campañas moralizadoras de Delfino compartieron también objetivos de la Liga de Profilaxis Social, creada en 1921 por Alfredo Fernández Verano a partir de un afán por volcar la obsesión predictiva de la eugenesia a la tenaz

19 ArÁoz Alfaro, G. (1920); «Demostración en honor del Profesor Víctor Delfino», La Semana Médica 14, 1 de abril, pp.473-476, p. 475.

20 Ibidem.

21 Delfino, V. (1923); «Memoria del instituto Tutelar de Menores, correspondiente al año 1922», La Semana Médica 12, 22 de marzo, pp. 559-566, p. 560.

22 Ibidem.

23 L.F.L.(1920); «El Instituto Tutelar de Menores de Buenos Aires», La Semana Médica 36, Buenos Aires, 2 de setiembre. En España otro eugenista, Luis Huerta, desarrolló tareas afines a las de Delfino impulsando el Grupo Benéfico Vallehermoso para la protección de la infancia. Véase Álvarez PelÁEz, R. (2004), «La búsqueda de un modelo institucional de protección a la infancia: Institutos, Guarderías y Hogares Infantiles. España, 1900-1940», en Perdiguero Gil, E. (ed.), Salvad al niño, Valencia, Seminari d'estudis sobre la Ciència, pp. 155-193. 
lucha por imponer el Certificado Médico Prenupcial obligatorio en Argenti$\mathrm{na}^{24}$. El propio Emilio Coni integró esa Liga y realizó traducciones de trabajos de eugenistas franceses como Adolphe Pinard, Alfred Fournier y Charles Burlureaux y Calmette, que fueron publicadas a través de numerosos folletos de divulgación. La cruzada eugénica ya contaba en sus filas con figuras centrales del campo político, intelectual y científico que, hacia 1920 y desde su actuación en el Museo Social, acentuaban los vínculos con los continuadores de la «Escuela positiva» italiana. Delfino tempranamente conoció los Institutos Nipiológicos (establecimientos para niños que maman y aún no hablan) creados por Ernesto Cacace en Capua (1905) y Napoles (1915) ${ }^{25}$ y pugnó porque Buenos Aires tuviera el suyo tras fundar en 1922 la Sociedad Argentina de Nipiología. Asimismo las visitas de Mariano Patrizi y Enrico Ferri a Buenos Aires, contribuyeron especialmente a alimentar interacciones con la realidad científica italiana por las que fue circulando en forma cada vez mas intensa la biotipología. Ella permeó un campo en el que ciertas aspiraciones políticas se ubicaron en directa relación con el protagonismo social de la corporación médica, y donde una sugerencia de Ferri podía derivar en 1923 en el propósito concreto de impulsar la creación en Buenos Aires de un Instituto Biotipológico atento al plan del creador de esa disciplina en Italia, Nicola Pende 26.

Por entonces la biotipología también había sido recepcionada por la antropología criminal, la sociología, la psicología, la psiquiatría, la psicotecnia, el derecho y el planeamiento. La eugenesia italiana imbuida de un vitalismo espiritualista de raíces tomistas, introducía una articulación inescindible de la parte con el todo, del cuerpo con la población, de la sexualidad con la reproducción, del grado de aptitud con la producción. Y lo hacía a través de un marco de reflexiones omnicomprensivas que, por encima de todas las cosas, buscaba integrar la biología con el poder. En ello parecía consumarse aquella vaga aspiración que Armus detectó en ciertas prefiguraciones del último Co-

24 Sobre la relación de la eugenesia argentina con la implementación del certificado médico prenupcial obligatorio, véase MiRANDA (2003).

25 Sobre la Nipiología véase Álvarez PelÁEZ (2004); op. cit.

26 Sobre la teoría de Pende puede verse: GALERA, A. (2005); «Hacia una fisiología del delito: el modelo biotipológico de Nicola Pende», en Miranda, M. y VALlejo, G. (comp.), pp.363-374. Sobre Pende y los Institutos biotipológicos que impulsó véase VALLEJO, G. (2004) y VALleJO, G. (2005), «Las formas del organicismo social en la eugenesia latina», en MirandA, M. y VALLeJO, G. (comp.); pp.231-272. Entre las primeras obras en las se presentó la biotipología se hallan: PENDE, N. (1922), La debolezze di costituzione. Introduzione alla patología costituzionale, Roma, G. Bardi, y PENDE, N. (1924); La biotipología umana, (scienza della individualita) $i$ suoi fondamenti, le sue aplicación, Palermo, Prometeo. 
ni, que desde la prevención higiénica iluminaban la idea de monitorear en forma panóptica el estado de normalidad sanitaria de toda la población. Es que efectivamente Pende y su corriente eugénica, concibieron el Instituto Biotipológico como un panóptico encargado de poner a prueba el estado de normalidad aparente, para detectar las anomalías que se escondían en las evidencias, o bien las «simulaciones», al decir de Ingenieros, que aparecían para confundir los roles que cada uno debía ocupar en la sociedad. El Instituto Biotipológico era una «clínica para sanos», un laboratorio escrutador en toda la población de «diversas predisposiciones morbosas, hereditarias o adquiridas y los temperamentos morbosos o submorbosos, que ponen en evidencia aquella serie infinita de anomalías y anormalidades, de debilidades y errores de la constitución y de la mente existentes o en estado latente» ${ }^{27}$.

Bajo este programa se iba tramando una estrategia biopolítica encargada de contrarrestar más que las epidemias, las endemias, las enfermedades más difíciles de extirpar por hallarse ocultas bajo un aparente estado de normalidad por condensar factores permanentes de sustracción de fuerzas, disminución del tiempo de trabajo, reducción de las energías, en suma de debilitamiento y degeneración. La biopolítica, en tanto tecnología que a través de la norma intervenía sobre el organismo y el cuerpo social, la disciplina individual y la regularización de la sociedad, encauzaba el conjuro de enfermedades sociales (físicas y/o morales) entendidas ahora como un fenómeno de la población. Y el principal foco se situaba en ese universo inasible de las patologías en estado latente, en las «predisposiciones morbosas» que en algún momento darían origen al mal que aparecía para corroer y alterar el orden social y biológico de la población, disminuyendo su vitalidad. El abordaje de esta problemática fue intensamente tematizado desde metáforas con las que el evolucionismo asoció la naturaleza a la sociedad, a través de la «lucha por la vida», la «selección natural», la «supervivencia del más apto» y la comparación del funcionamiento de la sociedad con los elementos constitutivos del organismo viviente, donde las células y los tejidos equivalían a los individuos y los grupos sociales. Y dentro de estas metáforas que participaron de la biologización de políticas de Estado, subyacía un claro propósito finalista: tutelar la sociedad para que actúe como un cuerpo controlable en el que sea eliminado el componente azaroso de la evolución.

En este proceso la reproducción, la natalidad y la morbilidad, en tanto problemas cruciales para el fortalecimiento de la raza, pasaron a condensar pre-

27 Barbara, M. y Vidoni, G. (1933); L'Instituto Biotipologico Ortogenético di Roma, Genova, Carlo Badiali e C., pp.5-6. 
ocupaciones centrales de un nuevo campo de estudios de la población. Desde 1930 la biopolítica en la Argentina se dirigió a contrarrestar aquellas expresiones que, como se creía, la crisis había contribuido a exponer claramente: la gran ciudad era causante de decaimiento racial y el campo era un espacio regenerador. Articular ambas variables y sumarlas a la inmigración externa, preparando estrategias para cuando ella se reanude, significaba ahora también atacar los principales males atribuidos a la vida moderna que, de manera muy diáfana, se asociaban a una decadencia moral que impactaba sobre la baja natalidad atribuida y sobre la inarmónica distribución de la población en el territorio.

El marco interpretativo surgido en esa coyuntura, afirmó una tendencia a biologizar los fundamentos de praxis sociales, a partir de la autorización «científica» que la política hallaba para intervenir en todos aquellos ámbitos que condicionaban la vida humana, en su faz productiva y reproductiva. Allí subyace una concepción holística que involucra la forma en que la política interrogaba el estado de salud de la población y buscaba «corregir» ambientalmente los más graves problemas atribuidos al conjunto de la población, desde las coerciones «benéficas» que el entorno ejercería sobre la moral individual. En este sentido, en las consideraciones de la ciudad y el campo y en los intentos de valerse de su incidencia sobre los individuos, a través de un determinismo ambiental que asignaba al espacio el rol de normalizar la moral, puede decirse que radican matrices centrales de una clara ideología. La misma que desde la higiene pública desplaza sus fundamentos hacia la eugenesia y desde 1930 ilumina el sentido unívoco que ésta adquiere en Argentina como una formulación de corte "neolamarkiano», que sirve a los fines de ampliar los espacios de intervención de políticas sanitarias inspiradas en la realidad italiana de entreguerras.

\section{INSTRUMENTOS IDEOLÓGICOS DE LA BIOPOLÍTICA: CULTURA LATINA, RAZA Y} FASCISMO

Cuando la «hora de la espada» anunciada por Lugones tuvo su encarnadura en el Golpe de Estado de 1930, la biopolítica adquirió una inusitada preeminencia en la Argentina. Pocos días después de la asonada militar, el médico fascista Nicola Pende dictó un curso en la Universidad de Buenos Aires y los médicos argentinos Octavio López y Arturo Rossi se trasladaron al Instituto Biotipológico de Génova — que el italiano había creado en 1926-, cumpliendo una misión oficial requerida por el Presidente Uriburu, a efectos de interiorizarse de los avances experimentados por la eugenesia en Europa y 
aplicarlos en la Argentina. Su estadía se prolongó hasta el año siguiente, en el que Benito Mussolini dejó inaugurado el Congreso Internacional de la Población de Roma, presidido por Corrado Gini y con la participación protagónica del propio Pende, donde se expusieron los fundamentos de la eugenesia italiana. Allí la representación oficial argentina ya se había incrementado notablemente con la presencia de otras figuras vinculadas al Museo Social: Enrique Ruiz Guiñazú, Carlos Brebbia y Guillermo Garbarini Islas. Ellos se sumaron a López y Rossi para conformar la delegación extranjera con mayor número de colaboraciones científicas.

Con el regreso de López y Rossi en 1932, nació en Buenos Aires la Asociación Argentina de Biotipología, Eugenesia y Medicina Social (AABEMS), bajo el claro objetivo de promover las acciones que en materia de eugenesia y población eran llevadas a cabo en países como Italia. Similar cruzada encaró el Museo Social Argentino que desde su nacimiento en 1912 había dado un lugar preponderante a estos temas dentro de una estructura de funcionamiento que incluyó, en el período de entreguerras, al Instituto de la Población dirigido por Carlos Bernardo de Quirós (antecedente directo de la Sociedad Argentina de Eugenesia nacida en 1945). Con ese anclaje institucional, el eugenismo argentino adquirió la forma de un campo bien delimitado por prescripciones que compartían principalmente médicos y abogados, pero también urbanistas, sexólogos, sacerdotes y pedagogos. Dentro de ese campo aparecía una coincidente preocupación por incrementar la tasa de natalidad, logrando que su resultado sea el producto de una tarea conciente, tanto de aquellos que debían reproducirse como de los que estaban llamados a evitar hacerlo para no crear futuras «cargas injustificadas» al país.

La AABEMS tuvo en Mariano Castex a su primer Presidente y a Nicola Pende como Primer Miembro Honorario corresponsal. En tanto que su órgano de difusión fueron los Anales de Biotipología que dirigió Arturo Rossi desde 1933. El primer referente internacional de la eugenesia argentina, Víctor Delfino, fue uno de sus miembros fundadores como también lo fueron figuras que habían creado la Liga de Profilaxis Social e intelectuales destacados del Museo Social. En la AABEMS participaron los médicos Gregorio Aráoz Alfaro, Ramón Carrillo, Oscar Ivannisevich, Josué Berutti, Gonzalo Bosch y Mariano Barilari, los pedagogos Víctor Mercante, Romero Brest y Ernesto Nelson, los abogados Bernardo de Quirós y José María Paz Anchorena, el ingeniero Nicolás Besio Moreno y el escritor antisemita Gustavo Martínez Zuviría, entre otros. La larga lista de miembros activos se completaba con corresponsales internacionales de Italia, Alemania, España, Francia y Brasil. En torno a esta Asociación, y sus derivaciones que además de los Anales 
comprendieron el Instituto y la Escuela de Biotipología — también dirigidos por Rossi-, el eugenismo argentino de los años `30 tuvo una clara filiación ideológica, evidenciada en su constante búsqueda de colocar los intercambios académicos con Italia al servicio de una activa diplomacia cultural, que asociaba los valores de la latinidad con los del fascismo.

Políticos y científicos argentinos coincidían en ponderar la importancia de una red latina cimentada en dos décadas de intensos intercambios, para que sirva ahora como instrumento útil a un expansionismo ideológico disimulado bajo el ropaje de la ciencia. La reconstrucción del Imperio romano ya no era una aislada prefiguración de Lugones, mucho menos cuando la Italia mussoliniana al hacer cada vez más explícito ese propósito hallaba fuertes consensos en la Argentina, allanados en gran medida por la receptividad de la biotipología.

Esta situación quedó particularmente evidenciada cuando los usos geopolíticos de las redes eugénicas tuvieron a la Argentina como un claro punto de tensión, desde el momento en que Estados Unidos trató de capitalizarlas para fundar mecanismos de control de la inmigración a través de datos genéticos y somáticos recabados para centralizar el conocimiento de la información racial de las poblaciones del continente mediante la Unión Panamericana. Para ello fue promovida la homicultura, vertiente eugénica que médicos cubanos lanzaron a comienzos de siglo junto al proyecto de un particular ámbito para la atención de su propia población, como era el Palacio de la Homicultura de La Habana y que más tarde fue impulsada especialmente desde los Estados Unidos para atender poblaciones externas: de ese afán surgió en 1927 la Primera Conferencia Panamericana de Homicultura en La Habana y en 1934 la Segunda en Buenos Aires ${ }^{28}$.

Frente a la avanzada de la eugenesia norteamericana en Argentina, Italia desarrolló una precisa política cultural que comprendía la búsqueda de afirmar una eugenesia latina que aúne naciones católicas americanas y europeas. Pende en 1934, ya convertido en Senador, convenció al Duce de organizar un «Ateneo Latino» para afianzar la «red espiritual» entre Italia y Argentina y llevar a cabo un «Congreso latino» en Buenos Aires con la presencia de 29 naciones, dividido en tres secciones: ciencia, bellas artes y ciencia aplicada. La contraofensiva de Pende trataba de afirmar una orientación a través de acciones que habrían de «representar para la Italia fascista el primer recono-

28 Sobre la Homicultura y la proyección de la eugenesia norteamericana en Latinoamérica, véase GARcía GonZÁlez y Álvarez Peláez (1999); y García GonZÁlez, A. y Álvarez PELÁEZ, R. (2007); Las trampas del poder. Sanidad, eugenesia e inmigración. Cuba y Estados Unidos (1900-1940), Madrid, CSIC. 
cimiento por parte de América latina de la preponderancia» que en adelante debía tener Roma en la dirección cultural de las naciones latinas» ${ }^{29}$, para regocijo de quienes como Lugones - pero también miembros de la AABEMS - esperaban en Argentina que eso efectivamente sucediera. Es que si entre la homicultura y la biotipología podían tramarse los objetivos de un expansionismo norteamericano y otro italiano, la absoluta primacía de esta última opción en la Argentina de los años `30 se sostuvo en gran medida por la persistente acción de la AABEMS apadrinada por Pende ${ }^{30}$. El avance de la Iglesia católica expresado en las enormes repercusiones del Congreso Eucarístico Internacional reunido en Buenos Aires en torno a las celebraciones del día de la raza de 1934, también fue un significativo avance para la estrategia cultural y eugénica italiana. Sobre todo porque tenía en el Padre Agostino Gemelli a un estrecho colaborador de Pende y al principal enlace entre el fascismo y el Vaticano. Las interacciones que la eugenesia entabló con el poder y la religión, se vieron favorecidas a su vez por el creciente protagonismo que asumía por entonces la figura del Cardenal Eugenio Pacelli, quien desde 1939 sería Pío XII.

El plan cultural del Duce tuvo una rápida aceptación entre los epígonos de Pende en Argentina y por impulso de Rossi pudo constituirse el Ateneo de Cultura Latina de Buenos Aires, con una Mesa Directiva integrada por Gonzalo Bosch, Paz Anchorena, Luis Tamini y Ángel Suárez. También se creó una Delegación de la AABEMS en Paraguay y se obtuvo el compromiso activo de sociedades vinculadas con la eugenesia de Brasil y Uruguay.

En 1934 Paz Anchorena visitó el Instituto Biotipológico de Génova para poner a Nicola Pende al tanto del avance de las tareas organizativas del «I Congreso Internacional de Cultura Latina en América» y dejarle en claro que él sería el Presidente académico del encuentro. Asimismo, las tareas desempeñadas por la diplomacia argentina en pos de afianzar esa red latina en América, determinaron que fuera su Presidente Honorario Carlos Saavedra Lamas, quien además de promover la creación de una Dirección General de Biotipología en estrecha vinculación con la AABEMS, era el Ministro de Relaciones Exteriores de la Argentina. Saavedra Lamas sería luego Premio Nobel de la paz en 1936 por su mediación en el conflicto limítrofe entre dos países integrantes de la red latina: Bolivia y Paraguay.

Nicolás Lozano, sucesor de Castex en la conducción de la AABEMS, consideraba al encuentro como «la primera manifestación en el mundo de una

29 Carta de Pende a Mussolini del 19 de noviembre de 1934. Cfr. ScarZanella, E. (1999), p.146.

30 VAllejo (2005). 
verdadera comunión de cultura de las naciones que tienen su origen en la civilización 'latino-mediterránea' $)^{31}$. Estaría destinado a ejercer «una real influencia en Sudamérica», con el fin de estar en comunicación con la Súper Universidad latina proyectada simultáneamente por Pende en Roma ${ }^{32}$.

El sustrato que favorecía este expansionismo basado en el culto a la latinidad, podía encontrarse también en expresiones del General Agustín P. Justo - sucesor de Uriburu en la presidencia de la nación_- quien podía saludar al Presidente del Brasil, Getulio Vargas, enfatizando una filiación ideológica y racial común: «nuestra condición de representantes de la Raza Latina en América, nos hace soldados de la misma civilización ${ }^{33}$. La AABEMS se identificó plenamente con este discurso - que publicó en sus Anales al darle una interpretación científica-, donde Justo además remarcó que «somos aquella misma recia estirpe romana, cuya influencia se extendiera sobre Iberia, transmitiendo su dinamismo y su inquietud a Portugal y a España para que dominaran los mares, haciendo surgir de su seno y de sus confines estas tierras, donde el ideal cristiano, para bien de la humanidad, había de tener realización definitiva y esplendorosa» ${ }^{34}$.

Dentro de esa red, España también pasó a ser un importante referente, especialmente desde los prolegómenos de la Guerra Civil. Precisamente la contienda puso de manifiesto no solo la colaboración militar de Italia con las fuerzas del General Franco sino también la solidaridad expresa de biotipólogos argentinos con ese bando. De hecho la figura de José Antonio Primo de Rivera, líder del falangismo español que lo tuvo como el «primer mártir» de las huestes antirrepublicanas tras ser fusilado en Alicante, sirvió a los fines de acentuar los vínculos con España. Biotipólogos argentinos e italianos se aunaron en homenajearlo, destacando que había pasado sus últimos días acompañado de un libro de Pende del que dejó una traducción en español para divulgarla entre quienes cultivaban los estudios biotipológicos ${ }^{35}$.

Para Rossi, España ocupaba un lugar preponderante debido a la «superioridad racial» que poseía y que compartía con Italia, con quien también pasó a compartir los afanes imperiales y el papel central del catolicismo invocados

31 Lozano, N. (1934), «Discurso de nuestro Presidente sobre la influencia de la Cultura Itálica en la República Argentina», Anales de Biotipología 28, pp.11-14, p.11.

32 Ibidem.

33 Justo, A. (1934), «Nuestra condición de representantes de la Raza Latina en América nos hace soldados de la misma civilización», Anales de Biotipología 29, p.3.

34 Ibidem.

35 VALLEJo (2004), p.235. 
por sus respectivos líderes. La «superioridad racial» española había sido trasladada a la Argentina a través de la conformación de "hogares cristianos» y «familias bien constituidas», que para Rossi no podía dejar de custodiar el Estado al diseñar nuevas políticas migratorias ${ }^{36}$. Estas ideas acompañaban a aquellas con las que figuras centrales del franquismo como el psiquiatría Antonio Vallejo Nágera, enmarcaba el levantamiento antirepublicano explicitando sus propósitos: «aspiramos al Imperio y universalizaremos nuestro pensamiento, nuestra literatura, nuestro arte, hasta que predominen en el mundo» ${ }^{37}$.

Semejante vocación expansiva que llegó a coexistir en Italia y España, sólo podía integrarse armónicamente a través del claro establecimiento de enemigos comunes y la participación central de la Iglesia Católica en la defensa del orden. De ahí que desde Argentina se naturalizara esa amalgama a partir de la imaginaria unión de esas naciones a una romanidad cristiana, sustentada en la precisa orientación cultural que la Italia fascista tempranamente había empezado a volcar en países americanos de ascendencia latina. Desde 1924 existía en Buenos Aires el Instituto de Cultura Itálica (ICI), el cual tuvo a su cargo la organización de distintos eventos culturales y conferencias ofrecidas por destacados intelectuales italianos. Precisamente había sido el ICI quien en 1930 trajo a la Argentina a Nicola Pende. Ese mismo año también invitó a M. Sarfatti para inaugurar una muestra de la «Pintura italiana en el Novecento» y en diciembre de 1933, por otra iniciativa del ICI, llegó al país P. M. Bardi para organizar la exposición «Arquitectura italiana de hoy», que tendría enormes repercusiones dentro de las vanguardias artísticas locales ${ }^{38}$. Bardi montó su muy influyente muestra en Buenos Aires, en la Comisión Nacional de Bellas Artes, ámbito orientado hacia coordenadas estéticas abiertamente opuestas a las del modernismo italiano que se presentaba, aunque muy afín a una estrategia de acercamiento político y cultural de ambos países, que puede seguirse en la figura del Director esa institución, el ingeniero Nicolás Besio Moreno, miembro fundador ese mismo año de la AABEMS. Pero es que

\footnotetext{
36 Ibidem.

37 Vallejo Nágera (1938) cfr. Llorente, A. (1995), Arte e ideología en el franquismo (1936-1951), Madrid, Visor, p. 32. Cerca del desenlace de la Guerra Civil, también el benedictino Fray Justo Pérez Urbel fue el publicicista de un arte que debía colocarse al servicio del Imperio por nacer. Y ya con el nuevo régimen instaurado Franco dio especial impulso a grandes monumentos conmemorativos, destacándose el «Valle de los Caídos», cuya ubicación fue decidida en 1940 cerca del Escorial para equiparar la magnificencia de ambas obras y de sus épocas «esplendorosas e imperiales».

38 BALleNT, A. y CRISPIANI, A. (1995); «Il racionalismo é vivo: 1'irruzione della nuova architettura italiana nell' Argentina negli anni trenta», Metamorfosis 25-26, pp. 56-62.
} 
además, la «eugenesia latina» que contribuía a catalizar estas relaciones diplomáticas dentro de una red de naciones unidas «espiritualmente» a Roma, establecía también curiosas articulaciones entre pasado y presente. Entre la vigencia del ideal de belleza clásico dentro de una raza invocada para recrear vínculos supranacionales «latinos» y la modernidad que emanaba de una exaltación de la novedad científica que podía ser interpretada estéticamente desde el futurismo italiano.

Con la explícita puesta en marcha del plan cultural de Pende para la Argentina, el ICI continuó generando actividades que alimentaban aquel propósito. En 1935 el arquitecto modernista Alberto Sartoris, llegó a Buenos Aires convertido en una suerte de embajador artístico del Duce, para exponer en sus conferencias un programa urbano que intentaba traducir a las formas el corporativismo social.

Si para Pende el Estado corporativo fascista era la expresión de un «sistema político verdaderamente biológico», donde prevalecía «la unidad de lo múltiple» y las desigualdades sociales eran naturalizadas al quedar parangonadas a las que existen entre los distintos tipos de células y tejidos que componen el organismo ${ }^{39}$, para Sartoris el modelo urbano correspondiente obedecía a la asignación precisa de la función que cada ciudad debía cumplir dentro del organismo social. En eso consistía la idea de «ciudad corporativa» que en Argentina fue calurosamente acogida por las élites dirigentes. Sartoris explicaba que «una economía controlada y organizada nos conduce a definir el deber productivo de la ciudad» y consecuentemente su tamaño. De ahí que el criterio corporativo implicara asignar a las ciudades «una población máxima de acuerdo a las diversas funciones en relación a la población de las provincias». Cada ciudad estaba sujeta a una estrategia que integraba las variables de calidad y cantidad - problema central de la eugenesia-, a través de la prefiguración de sus formas físicas (con un sentido funcional) y su capacidad poblacional que eran establecidas por un plan regulador ${ }^{40}$.

Vale decir que controlar el fenómeno urbano, implicaba establecer una función a la ciudad y fijarle sus límites en la convicción de que, por ese medio, se llegaba a la «organización corporativa del urbanismo que interesa a la ciudad, a la región y a la nación» ${ }^{41}$.

La «ciudad corporativa» canalizaba una precisa delimitación doctrinaria acerca del fenómeno urbano que el Ministro fascista, Giuseppe Bottai, esta-

39 Véase VALlEJo, (2005).

40 SARTORIS, A. (1935), «La ciudad corporativa», Revista de Administración Municipal, pp.3-15, p.14.

41 Ibidem. 
bleció prolongando el proceso de biologización y medicalización del Estado corporativo a la nueva disciplina concebida para el ordenamiento del territorio: «El urbanismo está en la urbs como la tisis en el cuerpo sano del hombre; pero la urbanística está en el urbanismo, como la tisiología está en tisis» ${ }^{42}$. La ciencia era el vínculo de una estrategia que unía la indagación de la ciudad en general como la del hombre sano individualmente para operar, invirtiendo la consideración de la anormalidad como una anomalía, sobre la presunción constante de la existencia del mal hasta tanto pudiera comprobarse el estado de normalidad. Esta patologización permanente de la cultura urbana que la biotipología pendeana acicateó, se empalmó muy bien en Argentina con un arraigado «clima antimetropolitano» ${ }^{43}$, asentado en otras tradiciones: fundamentalmente el organicismo de Patrick Geddes y sus articulaciones con la idea de «ciudad jardín» y el vitalismo biológico recepcionado, entre otras formas, a través del catolicismo social y de la difusión que el siempre influyente José Ortega y Gasset contribuyó a darle al pensamiento de Jakob Von Uexkull.

\section{DisPositivos DE LA BIOPOLÍTICA: LA REGENERACIÓN EXTRAURBANA}

Los estrechos lazos cultivados por las diplomacias argentina e italiana, mediados por el prestigio científico de Pende y de la AABEMS, también redundaron en 1933 en el proyecto de creación de un gran Preventorio en la Provincia de Buenos Aires. La propia denominación de la institución era indicativa de expectativas anticipatorias que animaban la búsqueda de detectar el mal en estado eventual a través de datos buscados en los caracteres externos, en la herencia y/o en el ambiente. Se trataba de una institución que en Italia y España recibió esa denominación para identificar a los asilos de niños débiles, aquellos que Coni llegó a promover para prevenir la tuberculosis. En Argentina igualmente ya existían Colonias de niños débiles desde que las creara el higienista José María Ramos Mejía en 1909 en los Parques Avellaneda y Lezama de la ciudad de Buenos Aires, siguiendo vagas prescripciones naturalistas inspiradas en postulados teóricos de la «Escuela nueva» ${ }^{44}$. Sin

42 Cfr. FinotTo, F. (2001), La città aperta. Storia delle teorie urbanistiche moderne, Venezia, Marzilio Editori, p.23.

43 BALlent, A. (2005), Las huellas de la política. Vivienda, ciudad, peronismo en Buenos Aires, 1943-1955, Buenos Aires, Prometeo-UNQ. Véase especialmente el capítulo III «El llamado del campo. ¿Urbanizar o ruralizar? El debate en la década de 1930», pp. 101-126.

44 A los dos primeros establecimientos le sucedieron otros dos creados también en Buenos Aires: uno en 1920 en Parque Chacabuco y otro en 1923 en calle Bompland y Loyola. 
embargo su limitada capacidad y su localización urbana fueron objeto de cuestionamientos que, desde la eugenesia, trataron de ser atendidos ajustando la institución a más estrictos patrones de funcionamiento indicados por el ejemplo italiano. Se trataba ahora de librar a la ciudad de individuos amenazantes, detectados con la mayor anticipación posible, para devolverlos, eventualmente, cuando el correspondiente tratamiento regenerador tuviera éxito. El programa buscaba extender sus alcances para que junto a Colonias de vacaciones y nuevas escuelas al aire libre, atendieran la «debilidad infantil», expresada según se creía casi unívocamente en cuerpos delgados y una convivencia en el ambiente «malsano» del conventillo que «conspiraba» contra «el futuro de la raza que se forma» ${ }^{45}$.

El nuevo Preventorio argentino fue visto por Raquel Álvarez en relación con el anterior Palacio de la Homicultura proyectado en La Habana, aunque cabe distinguir las diferentes vertientes eugénicas que representan y las funciones asignadas ${ }^{46}$ : mientras el palacio cubano concentraba todas las actividades de investigación y tratamiento, el emprendimiento argentino diseñado dos décadas más tarde era parte de un modelo concebido desde la especialización de la tarea de identificar las anomalías urbanas y tratarlas aisladamente en un centro regenerador situado fuera de la ciudad.

En efecto, el Preventorio argentino fue impulsado por la AABEMS en la localidad serrana de Tandil, situada a 370 kilómetros de Buenos Aires. Para su concreción se dispusieron de tierras obtenidas a través del Consulado italiano y del empresario local Pedro Redolatti, quien estaba también fuertemente relacionado con la máxima jerarquía eclesiástica de la que formaba parte su primo, Monseñor Fortunato Devoto ${ }^{47}$.

Al describir las funciones asignadas al Preventorio, era destacado su rol vinculado a la mejora de los «niños constitucionalmente débiles» y a aquellas

45 Primera Conferencia Nacional de Asistencia Social (1934), t.2, Buenos Aires, Kraft, p.161. El tema fue planteado en la Sección 32 del Encuentro: «La educación física en sus relaciones con la Asistencia Social», conformada por Ricardo Aldao, Enrique Romero Brest, Francisco Torino, Enrique Oliveri, Josué Berutti y Próspero Alemandri.

46 Álvarez PelÁEZ (2004), pp. 191-192.

47 Monseñor Devoto era astrónomo. En ese carácter se desempeñó al frente del Observatorio de La Plata en 1910, sucediendo al italiano Porro de Somenzi — estrechamente ligado a Víctor Delfino-, que fue alejado de esa institución por adherir a la tesis catatrofista del francés Flammarion que predijo la destrucción de la tierra el 18 de mayo de 1910 por el impacto del Cometa Halley. La condición de clérigo de Devoto favoreció su designación signada por la necesidad de apaciguar los ánimos de la población apelando a la fe y a la autorización científica de la institución que pasó a dirigir brevemente hasta ser reemplazo por Nicolás Besio Moreno. Véase VALLEJo (2006). 
«jóvenes madres vergonzantes que, por las circunstancias propias a su estado y a la condición precaria que las rodea, llegan al final de su embarazo, completamente exhaustas y son tanto ellas como sus hijos, víctimas de dolencias de suma gravedad ${ }^{48}$. De este modo cumpliría la tarea de recepcionar la esfera de anormalidad reconocida en las Maternidades y en las Escuelas de la Capital Federal y de la Provincia de Buenos Aires ${ }^{49}$.

La realidad metropolitana posibilitaba así detectar la patología presente o futura, real o eventual, en madres y niños, para que su aislamiento individual opere como instrumento de regeneración social. El funcionamiento orgánico de este sistema partía de establecer, entonces, dos ámbitos para el ejercicio de un control social totalizante e individualizado: las instituciones de Buenos Aires que habrían de registrar biotipológicamente a toda la población urbana y los sitios extraurbanos con clima benéfico que operarían como espacios de tratamiento y recuperación. Lozano explicaba ese funcionamiento que la AABEMS vendría a establecer conjuntamente con el Instituto de Biotipología, ámbito modélico de examen general y particularizado que, también en 1933, nació en el corazón de la metrópolis como una «clínica para sanos», 50 un dispositivos para la detección de lo «peligroso» que se escondía tras la apariencia de normalidad.

El principal instrumento era el fichaje biotipológico, consistente en la búsqueda de datos personales que articulaban pasado, presente y futuro: escrutaban sus características raciales, indagando especialmente la influencia hereditaria y recogían datos ambientales para dilucidar confesionalmente la faz espiritual y moral que, combinada con la orgánica, hacía posible vislumbrar próximas enfermedades y delitos. El fichaje biotipológico (aplicado desde ese mismo año en las Escuelas de la Provincia de Buenos Aires) y el Preventorio,

48 Lozano, N. (1933); «Preventorio Redolatti», Anales de Biotipología 16, p. 13.

49 El principal impulsor de la ficha biotipológica en las maternidades fue Juan B. González, Director del Instituto Maternal del Hospital T. Álvarez y autor de propuestas legislativas al respectó. Véase GonZÁLEZ, J. (1937), «La ficha antropogenética maternal. Necesidad y ventajas de su adopción», La Semana Médica 33, pp. 409-415; y GONZÁLEZ, J. (1940) «Eugenesia. La responsabilidad de la mujer respecto a la maternidad y la natalidad de la Nación respecto a dicha responsabilidad», La Semana Médica, 31, pp. 225-231. Sobre la aplicación de la ficha biotipológica en las escuelas de la Provincia de Buenos Aires a instancias de Arturo Rossi, véase VALLEJO (2006).

50 Hasta 1935 la AABEMS tuvo su sede central en la calle Alsina al 1027 y su Instituto de Biotipología en Avenida Corrientes y Uruguay. Debido al ensanche de la Avenida Corrientes en 1936 esos dos ámbitos se trasladaron a un local cedido por la Municipalidad en calle Suipacha al 1211, donde funcionó también la Escuela Politécnica de Biotipología, Eugenesia y Medicina Social. El Instituto Biotipológico, por su parte, se desplazó a Avenida Rivadavia al 1700. 
constituían así instrumentos complementarios de un mismo plan eugénico que implicaba articular lo urbano y lo rural, desde la convicción de que la primera era una entidad generadora de vicios y la segunda el necesario espacio de regeneración. El médico social era la indispensable figura que hacía falta para atender los males de la ciudad y organizar su cura fuera de ella. De esa forma actuaba ante el estado de anormalidad que comenzaba con la maternidad irresponsable, arrastrando «desgracias que constituyen, sobre todo en grandes ciudades, males constantes. Agréguese, además, que los niños que consiguen llegar a una edad mayor, son también, por el ambiente moral en el que se desarrollan, los eternos inadaptables, que mas o menos tarde van a poblar cárceles, hospitales o manicomios» $»^{51}$.

Una vez identificado lo patológico en la esfera reproductiva de la ciudad, el Preventorio vendría a atender «mujeres en desgracia» y la infancia que había sido abandonada por incumplimientos del mandato maternal. La acción asistencial sobre la enfermedad orgánica sería así tan importante como el ejemplo, el que tendría lugar reeducando «a las jóvenes madres en un ambiente moral, fortificándolas y dándoles una orientación de trabajo» ${ }^{52}$, a través de tareas agrícolas contempladas dentro de la nueva institución regeneradora.

Si bien la tuberculosis, como amenaza latente, buscaba ser contrarrestada a través de la acción benéfica del clima serrano, la respuesta biotipológica no se limitaba a atender ese mal sino que lo consideraba como una derivación de los verdaderos problemas que atacaba. El Preventorio iba más allá de ser un hospital antituberculoso para constituirse en una institución asilar que tendía a contrarrestar las condiciones morales e higiénicas que conducen a esa y otras enfermedades. Sería un establecimiento regido por la tranquilidad serrana para la cura preventiva y el descanso. Alojaría sí a tuberculosos, pero sólo como parte de un universo conformado por todos aquellos «candidatos» a esa enfermedad o al delito que eran detectados a tiempo. Es que anticiparse a la tuberculosis, en tanto enfermedad social, significaba para Lozano ocuparse de «sus víctimas predilectas», las madres «con taras orgánicas y morales y sus hijos». Pende explicaba cómo el examen biotipológico era revelador de enfermedades futuras: precisamente «el tipo humano que nosotros llamamos longilíneo asténico, está muy predispuesto a la tuberculosis pulmonar» ${ }^{53}$. Y del mismo modo que planteaba Pende, la estrategia apuntaba a encontrar el

51 LOZANO (1933), p. 13.

52 Ibidem.

53 Pende, N. (1932), «Orientación profesional, práctica, técnica y selección científica de los trabajadores», El Hospital Argentino 11, pp. 493-498, p. 496. 
mal antes que se haya manifestado, aquello que para Bottai era dar con la tisis en el cuerpo sano y con el urbanismo como patología de la urbs, para responder así desde la tisiología y la urbanística.

Con el Preventorio se pretendía asistir a la madre «anormal» y su hijo, robusteciéndolos «por medio de la vida del campo, en la cual el buen aire, la luz y la alimentación adecuada, restauran las fuerzas perdidas» y de «la educación moral y de trabajo que les ha faltado». ${ }^{54}$ Pero además de aglutinar el binomio madre e hijo, cuando éste se hallaba en su primera infancia, el Preventorio también recibiría niños solos en edad escolar que no superaran el examen del Instituto de Biotipología y por eso «requieran campo». Así se conformaría un establecimiento preventivo para mujeres y niños que por acusar «taras orgánicas» o malas influencias ambientales necesitaban un tratamiento asilar. Allí existiría un permanente control biotipológico para evitar que algún incumplimiento en ese tratamiento derive en futuros desvíos conductuales o sanitarios que se traduzcan en consecuencias sociales.

Tandil ya era un sitio emblemático para la salud, un lugar considerado entre los «más sanos» de la Provincia de Buenos Aires, a donde había recurrido Tomás Amadeo - fundador del Museo Social Argentino- para montar una institución educativa ejemplarizadora de sus ideales. Se trataba del «Hogar Agrícola», un Internado ideado en 1909 e inaugurado diez años mas tarde para la formación de maestras en todos aquellos conocimientos que debían transmitir a sus congéneres afincadas en la campiña, en la convicción de que medidas de ese tipo contribuirían a detener la urbanización y contener la población rural a través de una inquietud que era moralizadora y práctica a la vez. ${ }^{55}$ Se buscaba así establecer condiciones para asegurar la fijación de una familia «decente» en el campo, a través del papel multiplicador que tenía la acción femenina dentro del hogar, algo que Amadeo seguiría sosteniendo en

\footnotetext{
54 LOZANO (1933).

55 El «Hogar Agrícola» abrió sus puertas en 1919 en un edificio levantado sobre 100 hectáreas de tierra donadas por la viuda del terrateniente bonaerense, Ramón Santamarina. Poseía una huerta y un jardín, apiario, porqueriza y demás industrias de la granja, incluso un tambo y una pequeña instalación de productos de lechería. El programa en sí comprendía la instrucción general, economía doméstica, elementos prácticos de agricultura e industria casera, conceptos morales y de economía social, para «robustecer el sentimiento del hogar, la sencillez, la dignidad y el amor por la vida y los trabajos del campo». «El ambiente de la escuela estaba saturado del más alto espíritu social y cívico y era confortante comprobar el entusiasmo que todas las alumnas ponían en el cumplimiento de sus deberes y la fe casi religiosa que tenían en el éxito del apostolado a que su profesión las había de destinar». AMADEO, T. (1940), «La mujer en el Hogar Agrícola», Boletín del Museo Social Argentino 211-212, pp. 3-12, p. 8.
} 
las décadas siguientes para ensamblar esa idea con la muy difundida prédica dirigida en 1925 por Gina Lombroso - hija de Cesare - en pos de la moralización de la mujer ${ }^{56}$.

Si el «Hogar Agrícola» nació a partir de una clara predestinación del rol de la mujer en la afirmación de una armonía social vinculada al equilibrio entre el campo y la ciudad, el Preventorio que le sucedía aparecería para completar esa acción tutelar con la regeneración del binomio madre e hijo afectado por males de la vida metropolitana.

En el terreno destinado al Preventorio podían verse acrecentados sus beneficios regeneradores. Poseía una superficie de 9 hectáreas y se hallaba casi lindante al casco de la ciudad, a pocas cuadras de su plaza principal y de la Estación del Ferrocarril, permitiendo así una fácil accesibilidad que, empero, no alteraba el carácter natural de su entorno inmediato. A través del tren quedaría en permanente contacto lo urbano y lo rural, el Instituto de Biotipología y el Preventorio, asegurando la óptima conexión entre ambas realidades: la de la ciencia que en la ciudad detectaba lo patológico y la de la reclusión asilar que lograba la regeneración en un medio rural.

Situado en el remate de la Avenida principal, el Preventorio de Tandil disponía de un suelo rocoso, sobreelevado hasta conformar una colina que aseguraba la óptima circulación de aire puro y el control visual de la población. Precisamente esa era una obsesión de la medicina clásica reactualizada por que Nicola Pende a través de una teoría que podía ofrecer su directa consumación en el primer Instituto Biotipológico, que el italiano montó en 1925 en la Colina de San Álbaro, en las afueras de Génova ${ }^{57}$.

Con todas las ventajas atribuidas, el eugenismo argentino promovió aquello que a sus ojos no sería sino una verdadera institución modélica de la ciencia, una expresión emblemática de lo que ella podía hacer para «contribuir a afianzar la salud física, psíquica y moral del pueblo argentino». Su tratamiento biotipológico se fundaba en la vida al aire libre, una alimentación reparadora y prácticas físicas para reforzar el cuerpo. Para eso disponía de un tupido bosque de coníferas que desde la parte más alta «acompaña la inclinación accidentada del terreno sombrándola hasta su base, donde un ameno valle con sembrados y árboles frutales, viene surcado por un riachuelo rico de agua que lo atraviesa de Noreste a sudoeste, formando un paisaje soberbio y alegre ${ }^{58}$.

56 Lombroso, G. (1959), El alma de la mujer (primera edición, 1925), Buenos Aires, Emecé.

57 VALLEJO (2004).

58 MARChetTi, C. (1934); «Primer Preventorio para mujeres y niños débiles de la república», Anales de Biotipología 21, pp.4-5, p. 4. 
Sobre estas preexistencias naturales, el arquitecto Ciro Marchetti, realizó un ambicioso proyecto que, poco después de celebrada la muestra de arquitectura italiana que Bardi presentó en Buenos Aires en diciembre de 1933, expresaba una voluntad de situarse dentro de la misma sintonía estética del modernismo, exaltado por el fascismo como la representación del «nuevo orden». El complejo se compondría de una escuela para niños y talleres para que los más grandes aprendan un oficio según sus aptitudes intelectuales y su capacidad física, una pequeña chacra para contribuir a la economía del establecimiento y canchas de juegos al aire libre. El bosque y los jardines completarían un conjunto, donde los más pequeños podrían fácilmente «aclimatarse y sujetarse a la regularidad de la cura, a la necesaria disciplina médica, y crecer en un ambiente sano y libre para volver a la sociedad hombres fuertes y útiles a la patria» ${ }^{59}$. Y en el punto más alto de la colina, aquel que aseguraba el amplio control visual en el predio, se levantaría la Capilla.

El Preventorio, en definitiva, fue un emprendimiento de la AABEMS, formulado sobre la base de efectivas cooperaciones italianas, que buscaban a su vez acrecentar el consenso del cuerpo de ideas que representaban dentro del Estado argentino. Sin embargo, pese todas las coincidencias ideológicas que confluían en legitimar científica y políticamente una causa que expresaba de manera diáfana el propósito de propagar paralelamente el fascismo y la eugenesia, la concreción de las principales expresiones de este plan se vio inesperadamente interrumpida. Tanto el «I Congreso Internacional de Cultura Latina en América», presidido por Pende y previsto para que se celebrase en Buenos Aires el día de la raza de 1936, se postergaron hasta suspenderse definitivamente.

Ello se debió a la tensión ocasionada por la invasión italiana a Etiopía y al hecho de que, ante la condena internacional, la diplomacia argentina esgrimió un inesperado silenciamiento que sorprendió al Duce. Esa acción contrastaba con el apoyo generalizado de las élites de gobierno, que llegó a empalmarse con una encendida defensa de la política expansionista de Mussolini enunciada por Arturo Rossi en el comité Pro-Italia que creó y al que adhirieron figuras de importancia como el jurista Rodolfo Rivarola ${ }^{60}$. Eran estas, oscilacio-

59 Ibidem, p. 5.

60 SCARZANELla, E. (1999). Rodolfo Rivarola era un prestigioso jurista que en 1918 sucedió a Joaquín V. González en la Presidencia de la Universidad Nacional de La Plata hasta la irrupción de la Reforma Universitaria. Desde 1910 dirigió ininterrumpidamente la Revista de Ciencias Políticas de Buenos Aires. 
nes características de una cultura política argentina de entreguerras, que a menudo buscaba disimular el fuerte compromiso que efectivamente mantenía con la causa fascista, para pesar de miembros de la AABEMS y del propio Lugones que, incumplido su sueño imperial, se suicidó en 1938.

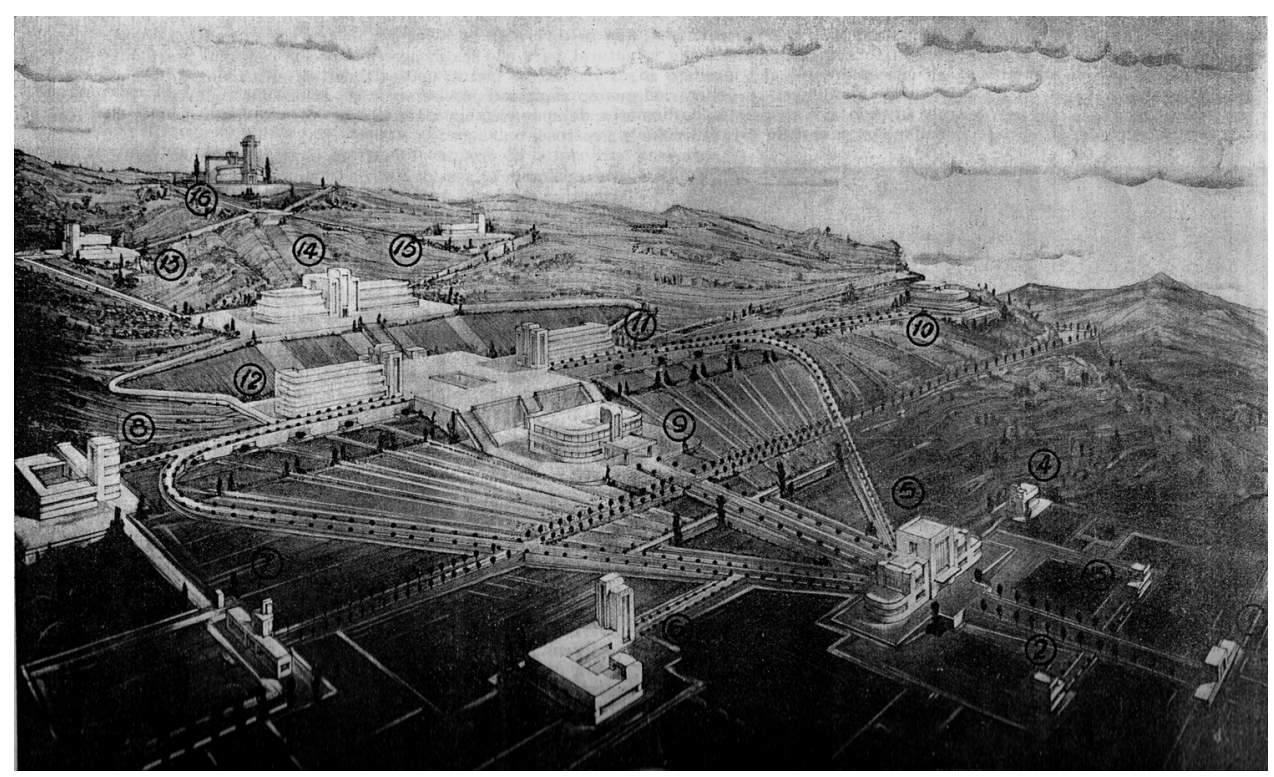

Preventorio para mujeres y niños débiles de Tandil. Proyecto del Arquitecto Ciro Marchetti, año 1933. Referencias: 1. Entrada y portería; 2. Casa del administrador; 3. Casa del Médico-Director; 4. Sala de autopsias; 5. Administración, consultorios, biblioteca, sala de operaciones; 6. Escuela de artes y oficios; 7. Campo deportivo; 8. Escuela primaria; 9. Pabellón de infecciosos; 10 . Cocinas y comedores; 11 y 12. Dormitorios con galería para niños; 13. Dormitorios con galerías para mujeres; 14. Baños; 15. Desinfección, lavanderos y guardarropas; 16. Capilla.

En reemplazo del «I Congreso Internacional de Cultura Latina en América», la Federación Internacional Latina de Sociedades de Eugenesia dirigida por Corrado Gini celebró su Congreso inaugural dentro de las actividades comprendidas en la Exposición de París de 1937.

Mas tarde la biotipología pudo dar cuenta del desarrollo alcanzado en Argentina cuando en 1940 y por impulso del Museo Social y la AABEMS nació el Primer Congreso de la Población (inaugurado por el vicepresidente en ejercicio de la presidencia de la nación, Ramón Castillo), correlato sudamericano 
del organizado unos años antes por Mussolini y Gini en Italia. Allí se ratificó la preeminencia de las tendencias desurbanizadoras en Argentina, ${ }^{61}$ adunada a un «poblacionismo selectivo» ${ }^{62}$, que integraba las variables eugénicas a las espaciales: el fomento a la natalidad sobre aquellos que poseían una «buena dotación genética» implicaba también ofrecer estímulos para trasladarse al campo y contrarrestar el exagerado crecimiento de las ciudades. El problema de la población sometido a diversos estudios durante el encuentro, eran fundamentalmente abordado desde la interacción de la vieja sentencia sarmientina de «el mal que aqueja a la Argentina es su extensión», con la alberdiana consigna de «gobernar es poblar». El punto de intersección se hallaba en las respuestas eugénicas requeridas, como lo remarcaba Tonina - miembro de la AABEMS. No era el aumento de la población en sí la meta sino el incremento de la calidad para conseguir, recién sobre ese sustrato, favorecer la natalidad. «La población debe encararse desde el enderezamiento de lo desviado o torcido, desde el desbrozado de la maleza insalubre, usurpadora y corruptora. Hay que desbrozar el campo antes de arar y antes de sembrar, porque siempre se ha visto que la alfalfa sucumbe a la maraña. Esto es empezar por los medios de la eugenesia, que debe no tender sólo a disminuir de la colectividad los elementos disgenésicos, sino a propiciar por todos los medios de salvaguardar la salud general y de beneficiar a los sanos, a los bien dotados, estimular a los buenos y mejores ${ }^{63}$. Si era necesario, debía echarse al inmigrante que no se integró e intervenir entonces sobre la denatalidad en la franja social «normal» que renunciaba a la reproducción por el avance del «masculinismo de la mujer» y el hogar indigno de las grandes ciudades ${ }^{64}$. La eugenesia allí debía contribuir a afirmar los roles de género cuando ellos se confundían y favorecer el acceso a una vivienda que asegure la conformación de familias «bien constituidas».

Dentro de este cuerpo de ideas se ubica la apelación al barrio jardín como una libre adaptación local del planeamiento organicista anglosajón, que reco-

61 En ese aspecto, el Congreso de la Población prolongó las ideas centrales que habían sido formuladas en la Primera Conferencia Nacional de Asistencia Social de 1933, en la Sección $4^{\circ}$ : «Urbanismo social», que estuvo a cargo de figuras mayoritariamente vinculadas a la Comisión Nacional de Casas Baratas creada por el Estado nacional en 1915: Juan F. Cafferata, Carlos Coll, Juan Ochoa, Gregorio Aráoz Alfaro, Benjamín Nazar Anchorena y Eduardo Lanús. Primera Conferencia Nacional de Asistencia Social (1934), pp. 31-35.

62 Miranda (2005), pp. 189-218.

63 ToninA, T. (1941), «El Congreso de la Población y el panorama sanitario argentino», La Semana Médica 14, pp. 769-781, p. 773. La cursiva es de Tonina.

64 Ibidem, p. 776. 
gía sugerencias vitalistas e ideas instaladas en el propio corpus de la biotipología pendeana para sanear los centros urbanos. El Instituto de Colonización de la Provincia de Buenos Aires, creado 1937 por el Gobernador Manuel Fresco - un médico higienista que llegó a mantener directas vinculaciones con Mussolini- se ubicó dentro de esta tendencia. Y también lo hicieron distintos intentos de materializar viviendas-granja (incluidos proyectos presentados por el diputado católico Juan F. Cafferata al Congreso Nacional) para corporizar la idea de «casa eugénica» de Pende. El propio Tonina propiciaba desde el «Congreso de la Población» realizar viviendas-granja o granja familiar en el medio suburbano y rural para conformar el «centro económico y moral del mayor valor, expresión de una cultura sana y un alto concepto de bienestar para la felicidad del porvenir», puesto que ellas serían el mejor medio para producir el «afianzamiento de la familia» y recrear la seguridad social ${ }^{65}$. Estas ideas marcaron el tono de un debate acerca que cómo debía actuar el Estado argentino para contener el acelerado proceso de masificación, contrarrestando a la vez el problema atribuido a la denatalidad ocasionada por el trajín de la vida moderna.

El poblacionismo que regía todas estas reflexiones, estaba fuertemente influenciado por distintos tipos de estímulos instituidos por el Estado fascista para favorecer la prolificidad, sobre todo después de la conquista de Etiopía, cuando el aumento de la población pasó a estar directamente relacionado con la protección del imperio que se buscaba recrear ${ }^{66}$. También con el esfuerzo del franquismo por recomponer las población española, tras la Guerra Civil y la depuración de republicanos producida en la posguerra a través del exterminio o el exilio.

La articulación que en Argentina se buscó entre la matriz poblacionista italiana y española y la vivienda extraurbana, presidió las consideraciones suscitadas por el «Congreso de la Población», prolongándose en el pensamiento y la acción de figuras como Carlos Bernardo de Quirós. En efecto, desde las funciones que ocupaba en el Banco Hipotecario Nacional, Quirós pudo imaginar la forma en que esa institución debía colocarse al servicio de un plan para proveer de la «casa eugénica», asignando préstamos oficiales sin interés a parejas en trance de matrimoniarse siempre y cuando manifestaran deseos de «repoblar

65 Ibidem; p. 779.

66 Miranda alude también a la faceta complementaria que tuvo ese poblacionismo con los castigos a la no-reproducción eugénica, por ejemplo a través del impuesto a los «célibes aptos», a los solteros y los severos cuestionamientos a la «mujer moderna» por incumplir cxon los debereas de la maternidad y el hogar. MIRANDA (2005). 
nuestra campaña y laborar la tierra», siendo cancelables al nacer el tercer hijo vivo, debiendo además ser todos argentinos. Era condición básica «poseer condiciones fisiológicas, eugénicas y morales, de propagar la especie», quedando excluidos del plan de vivienda los enfermos de ambos sexos, los «débiles orgánicos, los anormales, los ancianos, o viejos prematuros», los que no quisieran tener hijos o sólo quisieran tener uno, los que no tuvieran hábitos sólidos de trabajo remunerado, los que no tuvieran sosiego y espíritu hogareño, los que no se enraizaran definitivamente en nuestra tierra, «los caducos, los impotentes, los castrados», y en general «los indeseables para la Nación, porque ellos no representan un valor positivo para la especie» ${ }^{67}$.

En ese contexto, la revista argentina Hijo mío! podía presentar como prototipo de familia eugénica a la de Gustavo Martínez Zuviría - miembro de la AABEMS y Director de la Biblioteca Nacional entre 1931 y 1955, antecediendo en ese cargo a Jorge Luis Borges - que modélicamente posaba junto a su esposa y sus 12 hijos «sanos» en el lanzamiento de un certamen que en 1937 pasó a premiar a familias numerosas. Asimismo, en la Revista de Arquitectura, su Director, José M. F. Pastor, participaba de los debates por la transformación de la Comisión Nacional de Casas Baratas que llevaba a cabo el Coronel Juan Domingo Perón en la Secretaría de Trabajo y Previsión Social. Desde un planeamiento organicista sustentado en el vitalismo biológico, Pastor promovía el desarrollo de la «familia normal», aquella que desde su perspectiva lo era tanto más por cada hijo que agregara a la media de tres, apelando para ello a un ejemplo «interesante en estos tiempos en que tanto preocupa el tema de la denatalidad». Ese ejemplo contenía toda una definición del ideal de familia y de su localización espacial, al tratarse de una vivienda para matrimonios con 16 hijos, una suerte de pequeño hotel que el Estado había adjudicado en campos asturianos ${ }^{68}$. Es que precisamente el Instituto Nacional de la Vivienda de España desde su creación en 1939 (en reemplazo de la anterior política social de Casas Baratas) desplegó explícitos propósitos poblacionistas, enfatizando la prolificidad como factor prioritario en el otorgamiento de casas a una renta reducida, e instituyendo como Premio anual el obsequio de diez viviendas situadas fuera de las grandes ciudades a las familias que reunían más hijos en el hogar ${ }^{69}$.

67 Bernaldo De Quirós, C. (1942); Problemas demográficos argentinos, Buenos Aires, p. 48.

68 «Proyecto de construcción de viviendas para matrimonios con 16 hijos, en Asturias. Arquitecto: Carlos de Miguel» (1945), Revista de Arquitectura, mayo, p. 211.

69 Como balance del accionar de ese organismo español hasta 1947, el gobierno franquista publicó la obra compilada por ARTAJO J. (1947), Viviendas protegidas. Directrices del 
Como en Italia y en España, el pro-natalismo y el cuestionamiento al ambiente metropolitano se impusieron en Argentina en una agenda social que, a fines de los años '30, tendía a desplazar en las preocupaciones de la AABEMS a la tuberculosis y su cura como tema central, a medida que adquirían una cierta autonomización vinculada a precisas localizaciones ${ }^{70} \mathrm{y}$ el eugenismo desde su articulación con el poblacionismo podía expandirse a esferas mucho más vastas de intervención. Como quedaba en claro, aquel tratamiento sanitario provisto por el Preventorio no obedecía a una precisa enfermedad sino a una necesidad más amplia de moralizar las formas de vida urbana a través de una acción tutelar desplegada sobre fragmentos de la sociedad sospechados de producir futuras «degeneraciones» en el orden social y biológico. Y siendo esto así, aún cuando fuera ideado casi como una ciudad de reclusión, un establecimiento de esas características, con una demanda de atención tan vaga y generalizada, pronto se hubiera visto desbordado.

El fichaje biotipológico igualmente siguió buscando los «niños débiles», si no predispuestos a la tuberculosis, candidatos a otras enfermedades o al delito. Tonina aspiraba a que, de la misma forma que existía un registro personal a través de la cédula de identidad, se creara otro con la ficha familiar, implementado a partir de la transformación de la Oficina Central de Censo en un Instituto de Investigaciones Demográficas, regido por la eugenesia, la herencia, la sociología y el Derecho. ${ }^{71}$ Y complementariamente debía actuar un Instituto de la Población Argentina, compuesto por sacerdotes, médicos, militares, maestros, juristas, economistas, arquitectos y legisladores ${ }^{72}$.

El objeto de atención del Preventorio se prolongaría luego, aunque con más acotados alcances, a través del afianzamiento como institución de la Colonia de niños débiles. Estas tendrían localizaciones desplazadas principal-

régimen de protección a la vivienda, Madrid, Formularios. Ella contiene imágenes de conjuntos inaugurados y las tipologías de vivienda utilizadas, donde cabe destacar que no existían unidades previstas para matrimonios con menos de 4 hijos.

70 Por entonces las sierras de Córdoba concitaban los principales ámbitos para el tratamiento de la tuberculosis, donde prevalecía el Sanatorio Nacional Santa María de Cosquín, desarrollado sobre casi 400 hectáreas y unos 1.000 internados, constituyendo para Armus uno de los sanatorios más grandes del mundo. Véase ARMUS, D. (2006), «Curas de reposo y destieros voluntarios. Narraciones de tuberculosos en los enclaves serranos Córdoba», en BONGERS, W. y OlBrich, T. (cmps.); Literatura, cultura, enfermedad, Buenos Aires, Paidós, pp. 115-138.

71 TONINA (1941), p. 772.

72 Ibidem, p. 775. 

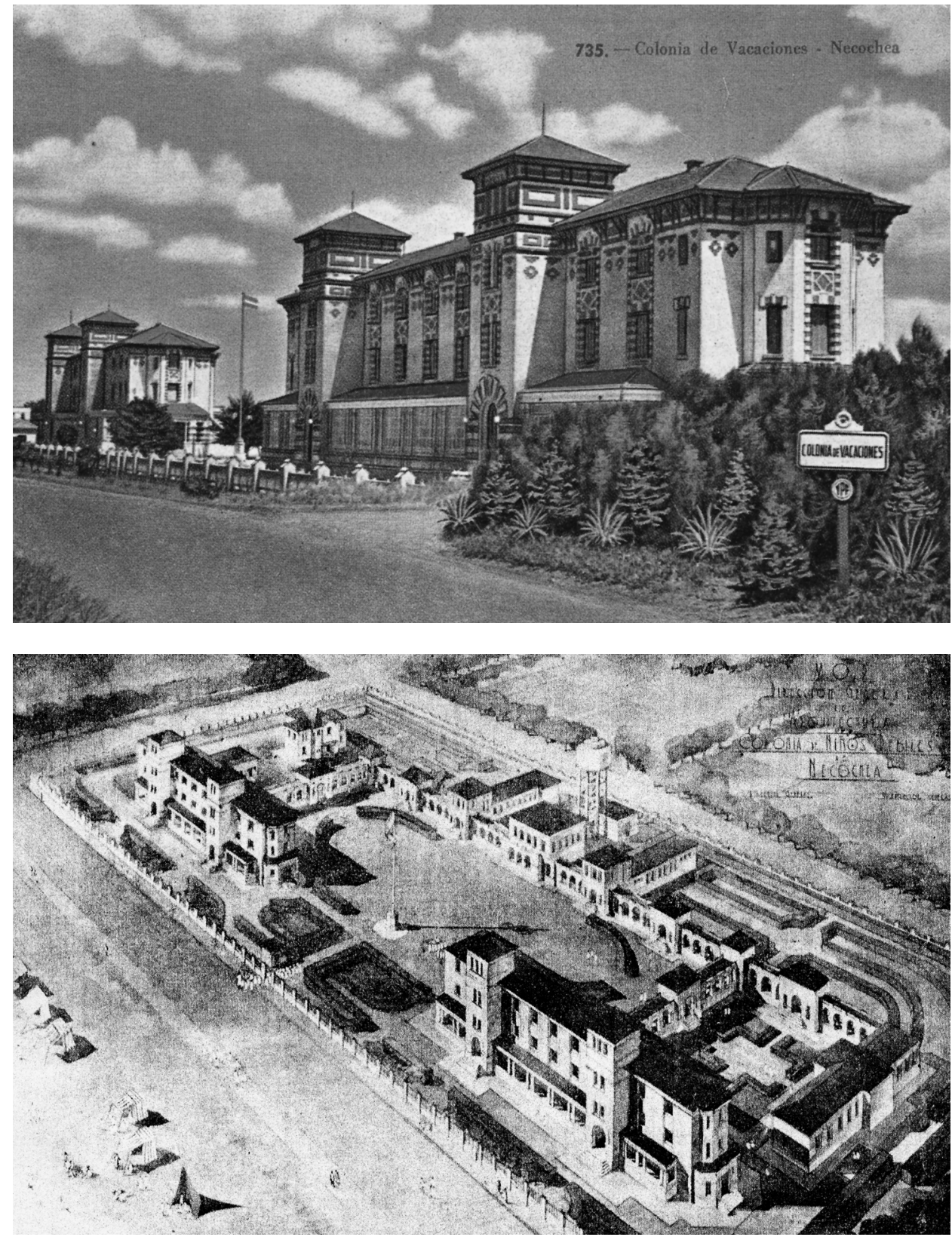

Colonia de niños débiles de Necochea, Provincia de Buenos Aires. Década de 1930. 
mente hacia el mar, como es el caso del establecimiento social creado frente a las playas de Necochea a comienzos de los años `30 y ampliada a fines de esa década ${ }^{73}$.

Los cambios sobrevenidos formaron parte del surgimiento de un nuevo fenómeno, el turismo social, que comenzó a ser impulsado por el Estado para morigerar la desocupación que reinaba por efecto de la crisis del `29, reduciendo la jornada laboral y creando destinos capaces de absorber el nuevo tiempo libre de los asalariados. Era en gran medida, y sobre todo como podía apreciarse explícitamente en las políticas sociales impulsadas por Manuel Fresco, una versión argentina del Doppolavoro que instituyó Mussolini para colocar el ocio masivo dentro de un programa extensivo de paternalismo social.

Pero el Preventorio también dejó otras claras resonancias de sus propósitos en Tandil, cuando el predio donado a la AABEMS para llevar a cabo aquellas funciones asistenciales fue objeto de una nueva propuesta, articulada también con los ideales disciplinadores perseguidos a través del nuevo turismo social.

Lo que iba a ser el Preventorio finalmente devino en el Calvario, el monumento religioso a cielo abierto más grande de la Argentina, levantado sobre la colina que Redolatti había pensado destinar a la «formación de un barrio, santuario y colonia de vacaciones para niños débiles». En el punto más alto, aquel que representaba la aspiración de la biotipología de controlar visualmente la población urbana, se ubicó la enorme cruz de 22 metro de altura, como destino de un Vía Crucis que reproducía las escalas en el monte Gólgota. La propuesta tuvo un impulso decisivo en Monseñor Fortunato Devoto, Elisa Alvear de Bosch y fue ampliamente forestado por decisión del Director de Parques Nacionales Exequiel Bustillo ${ }^{74}$. En tanto que su hermano, el Ar-

73 Las Colonias de niños débiles, como la de Necochea frente al mar, continuaron una labor en la que Silvia Di Lisia ha visto cambios vinculados al programa social del peronismo, que, desde su perspectiva, hizo prevalecer la función asistencial y turística por sobre un anterior criterio asilar de sesgo eugénico. Di LiSIA, M. (2006); «Colonias de niños débiles. Los instrumentos higiénicos para la eugenesia», en Di LisIA, M. y BoHOSLAVSKY, E. (ed.); Instituciones y formas de control social en América Latina. 1840-1940, Buenos Aires, Prometeo, pp.93-114. Aún así, y en todo caso desplazado a otros ámbitos, no puede dejar de advertirse la importancia central que tuvo la eugenesia dentro de la estructura del peronismo: RAMACCIOTTI, K. (2005), «Las huellas eugénicas en la política sanitaria argentina (1946-1955)», en MIRANDA, M. y VALLEJO, G. (comp.), pp. 311-350

74 Después de su actuación en el Observatorio de La Plata, Devoto desarrolló una intensa carrera eclesiástica y astronómica que hacia 1936 lo tenía como Monseñor y como Director del Observatorio de san Miguel creado a partir de vinculaciones con el Observatorio del Ebro, importante institución científica de la Compañía de Jesús en España. Devoto también era 
quitecto Alejandro Bustillo, sumaría en 1943 a su galería de importantes intervenciones arquitectónicas y paisajísticas sobre los principales lugares turísticos nacionales - Misiones, Bariloche, Mar del Plata - la realización del Calvario de Tandil, tras viajar especialmente a Jerusalén para conocer el sitio sagrado que su obra reprodujo ${ }^{75}$.

El programa eugénico concebido a partir de la detección de anormalidades para la mejora de sus síntomas por efecto benéfico del clima serrano, devenía en un gran monumento religioso. La vigorización del cuerpo afectado por males urbanos dejaba lugar a una escenográfica manifestación de los valores católicos. Eran dos expresiones del afán de la cultura argentina de los años $` 30$ y `40 de crear modélicas respuestas extraurbanas para mejorar la raza argentina, atendiendo al cuerpo y el alma, afectados por un mal atribuido a la «degeneración» de la vida moderna producida en la metrópolis.

De esta preocupación derivaba la inquietud cierta por favorecer el traslado de la ciudad al campo «regenerador» para lograr una más equilibrada distribución poblacional: en un territorio nacional de $3.000 .000 \mathrm{~km}^{2}$ habitaban poco más de 12 millones de habitantes de los cuales mas del 50\% se concentraba en Buenos Aires y el litoral. Sin embargo, la idea de que los estímulos a la desurbanización compensarían esos desequilibrios y redundarían en un aumento en los índices de natalidad, pronto se desvaneció: los grandes latifundios que existían desde que la «conquista del desierto» consumó la «solución final» a la presencia indígena y liberó tierras que quedaron a expensas de una clase militar y política, constituía un claro impedimento para el plan desurbanizador. Algo que enfáticamente le señalará a los biotipólogos Bartolomé Bosio, un anarquista de larga trayectoria como médico rural ${ }^{76}$.

Presidente de la Comisión Nacional de Observatorios y miembro de la Comisión encargada de medir un Arco meridiano en Argentina. Véase VALLEJO, G (2006). Por su parte, Elisa Alvear de Bosch era cuñada del eugenista Gonzalo Bosch, hasta 1936 había sido Presidenta de la Sociedad de Beneficencia y desde entonces presidía la Sociedad católica de San José. En tanto que la figura de Exequiel Bustillo se destaca en Argentina por el rol central ejercido en una insistente tarea de creación de Parques Nacionales.

75 La obra se completó con 17 estatuas realizadas por importantes artistas del momento: José Fioravanti, Carlos De la Cárcova, Horacio Cerantonio, Santiago Berna, Pedro Tenti, Roberto Capurro, César Sforza, Ernesto Soto Avendaño y Ricardo Musso. Sobre la trayectoria de Bustillo y su papel en la arquitectura argentina véase RAMOS, J. (1995), «Bustillo», Cuadernos de Historia 6, Buenos Aires, Instituto de Arte Americano; y GutiÉRREZ, R (dir.) (2005); Alejandro Bustillo: la construcción del escenario urbano, Buenos Aires-La Plata, Cedodal y Gobierno de la Provincia de Buenos Aires, 2005.

76 Bosio, B. (1942), «La realidad demográfica de nuestro país», La Semana Médica 31, pp. 249-262. 

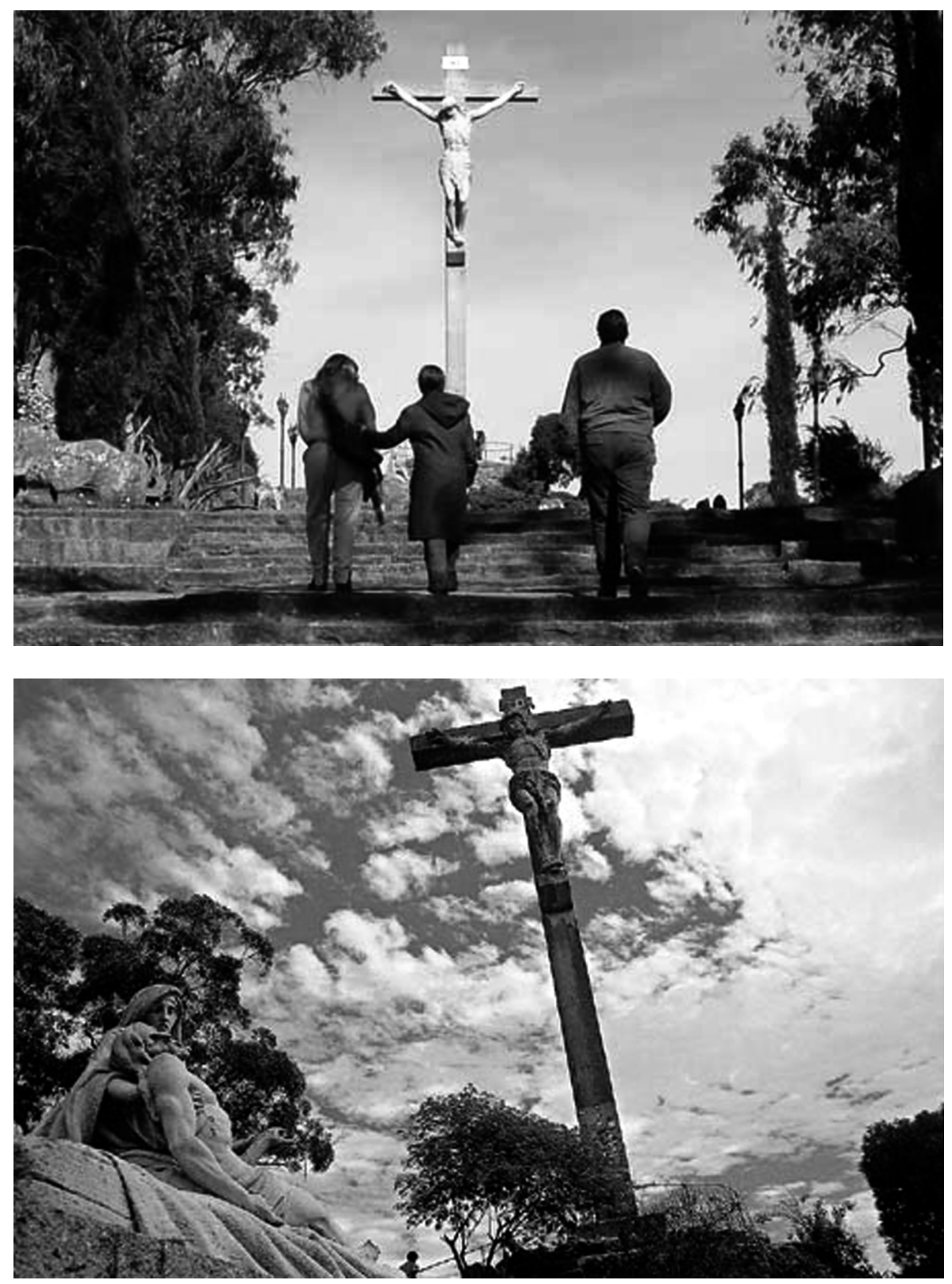

Calvario de Tandil, Provincia de Buenos Aires. Proyecto del Arquitecto Alejandro Bustillo, año 1943. 
Igualmente sobre ese sustrato biopolítico, el peronismo podrá levantar buena parte de los íconos mas impactantes de su gestión, fundados en la vigorización del cuerpo a través de un imaginario que comprendió la exaltación del mundo extraurbano con el barrio jardín y el chalet (otorgado a través de préstamos del Banco Hipotecario Nacional), como idealizadas tipologías de vivienda para sectores bajos y medios, y con las colonias de vacaciones como instituciones integradas al turismo social que conformará un vasto programa de ocio masivo en las sierras y el mar.

En el peronismo confluían así derivaciones directas de la eugenesia a partir de tres décadas de una vasta influencia ejercida sobre las culturas científica y política de Argentina. El marcado carácter ambiental y "neolamarkiano" que adoptó esta experiencia eugénica, imbuída de un claro sesgo confesional y de estrechas vinculaciones con el fascismo italiano, seguirá propiciando una proyección de sus alcances hasta comprender crecientes espacios de intervención: custodiar la salud física y moral de la población y conformar la verdadera raza argentina, combinando el pro-natalismo con las exclusiones y la asignación del justo lugar que cada uno debía ocupar dentro del organismo social, continuó siendo un mandato de políticas educacionales, sanitarias, demográficas y territoriales.

Fecha de recepción: 6 de septiembre de 2006

Fecha de aceptación: 20 de noviembre de 2006 
